Published in final edited form as:

Expert Rev Mol Med. ; 13: e24. doi:10.1017/S146239941100189X.

\title{
Smith-Lemli-Opitz Syndrome
}

\author{
Andrea E. DeBarber ${ }^{1}$, Yasemen Eroglu ${ }^{2}$, Louise S. Merkens ${ }^{3}$, Anuradha S. Pappu ${ }^{1,3}$, and \\ Robert D. Steiner ${ }^{3,4}$ \\ ${ }^{1}$ Department of Physiology and Pharmacology, Oregon Health \& Science University (OHSU), \\ Portland, OR 97239 \\ ${ }^{2}$ Department of Pediatric Gastroenterology, OHSU \\ ${ }^{3}$ Department of Pediatrics, OHSU \\ ${ }^{4}$ Department of Molecular \& Medical Genetics, Child Development and Rehabilitation Center, \\ Doernbecher Children's Hospital, OHSU
}

\begin{abstract}
Smith-Lemli-Opitz syndrome (SLOS) is a multiple congenital malformation/intellectual disability syndrome, with clinical characteristics encompassing a wide spectrum and great variability. Elucidation of the biochemical and molecular genetic basis for the autosomal recessively inherited SLOS, specifically, understanding SLOS as a cholesterol deficiency syndrome caused by mutations in DHCR7, opened up enormous possibilities for therapeutic intervention. When cholesterol was discovered to be the activator of sonic hedgehog, cholesterol deficiency with inactivation of this developmental patterning gene was thought to be the cause of SLOS malformations, yet this explanation is overly simplistic. Still, despite these important research breakthroughs, there is no proven treatment for SLOS. Better animal models are needed to allow potential treatment testing and the study of disease pathophysiology, which is incompletely understood. Creation of human cellular models will surely be useful, especially models of brain cells. In vivo human studies are essential as well. There have only been limited natural history studies of SLOS to date. Biomarker development will be critical in facilitating clinical trials in this rare condition, since clinical phenotype may change over many years. Additional research in these and other areas is critical if we are to make headway towards ameloriating the effects of this devastating condition.
\end{abstract}

\section{Keywords}

congenital malformation/intellectual disability syndrome; cholesterol deficiency; 7dehydroreductase; DHCR7; dehydrocholesterol

\begin{abstract}
Smith-Lemli-Opitz syndrome (SLOS) is a multiple congenital malformation syndrome that was first described by Smith, Lemli and Opitz in 1964 (1). Many hundreds of SLOS cases have been reported since that time, leading to the recognition of SLOS as a relatively
\end{abstract}

\footnotetext{
Further reading, resources and contacts:

In addition to references (24-32), SLOS pertinent websites include;

The Smith-Lemli-Opitz/RSH Foundation website: http://www.smithlemliopitz.org/

GeneReviews website (SLOS article): http://www.ncbi.nlm.nih.gov/books/NBK1143/

emedicine website: http://emedicine.medscape.com/article/949125-overview

Steiner Laboratory website:

http://www.ohsu.edu/xd/health/services/doernbecher/research-education/research/research-labs/robert-steiner-lab.cfm

RDCRN Sterol and Isoprenoid Research consortium website: http://rarediseasesnetwork.epi.usf.edu/STAIR/index.htm
} 
commonly cause of malformation syndrome. The clinical characteristics of SLOS encompass a wide spectrum. It can be inferred, from the great disparity between incidence estimates for the genetic defect and SLOS patients identified, that more severely affected infants often die in utero or in the perinatal period due to multiple congenital malformations, while more mildly affected patients suffer from only minor physical anomalies and characteristic learning and behavioral issues. Although SLOS was suggested to be an autosomal recessive inherited disorder shortly after it was identified $(2 ; 3)$, a major clue to the underlying genetic defect was not provided until 1993, when $>1000$-fold the normal concentration of 7-dehydrocholesterol (7-DHC; cholesta-5,7-dien-3 $\beta$-ol) was found in the plasma of a SLOS patient (4). The biochemical profile of this patient and 4 others was consistent with deficient activity of 7-dehydrocholesterol reductase (DHCR7; demonstrating7,8-reductase activity), an enzyme that normally converts 7-DHC to cholesterol the final step of the cholesterol biosynthetic pathway $(5 ; 6)$. In a short period of time the enzyme deficiency was proven in SLOS (7); the human DHCR7 gene (GenBank accession number AF034544) was cloned and localized to chromosome 11q12-13 (8), and SLOS causative mutations in $D H C R 7$ were independently reported by three groups of investigators (9-11). Gene knock-out mouse models for SLOS have since been generated which recapitulate aspects of the human disorder (null mutations $D h c r 7^{\wedge 3-5}$ (12) or Dhcr $7^{\text {delEX8 }}$ (13) or hypomorphic mutation $\left.D h c r^{\wedge}{ }^{\wedge-5 / T 93 M}(14)\right)$. In addition, rodents treated with DHCR7 inhibitors provide another model for studying SLOS $(15 ; 16)$.

There is still much to learn regarding the pathophysiological processes that occur in SLOS. The effect of cholesterol deficiency in SLOS patients is being actively studied, in particular the effect on brain structure, function and development, in utero and from birth to adulthood. Although circulating concentrations of cholesterol can be normal in some patients (likely from residual endogenous cholesterol synthesis fortified with exogenous cholesterol from the diet) the inability of cholesterol to cross the blood-brain-barrier suggests brain cholesterol is deficient in most SLOS patients. Adequate cholesterol is not transferred across the placenta to normalize circulating cholesterol in DHCR7 deficient fetuses, and severely affected SLOS newborns can have plasma cholesterol concentrations as low as $1 \mathrm{mg} / \mathrm{dl}(2 \%$ of normal in newborns) (17), with cholesterol deficiency found in all tissues, especially brain tissue. Fetal cholesterol is also thought to be low during embryogenesis with malformations occurring in tissues and structures whose embryonic patterning depends on signaling by the Hedgehog family of secreted proteins, after these proteins are activated by cholesterol (18). Insufficient cholesterol during embryogenesis with resultant deficient activation of Hedgehog signaling, however, is an overly simplistic explanation, as noncholesterol sterols can also activate sonic hedgehog.

Cholesterol deficiency is a trait shared by other malformation syndromes caused by cholesterol synthesis defects including desmosterolosis, lathosterolosis, HEM dysplasia, Xlinked dominant chondrodysplasia punctata, CHILD syndrome, SC4MOL deficiency, and Antley-Bixler syndrome (reviewed recently (19)). While these disorders share some developmental and clinical characteristics, their manifestations are quite varied, suggesting that the unique biochemical intermediates that accumulate in each disorder may play an important role in disease pathophysiology. The role of accumulated 7-DHC in SLOS, and potentially bioactive or toxic oxysterols $(20 ; 21)$ and sterols $(22 ; 23)$ generated from the ready oxidation of 7-DHC, is being currently explored.

There have been a number of informative reviews of SLOS syndrome published (24-32). Here we will focus on recent advances in our understanding of cellular and molecular mechanisms in SLOS and the clinical implications of this knowledge. 


\section{Biochemical Phenotype of SLOS}

The human DHCR7 enzyme reduces the 7,8 unsaturated bond of 7-DHC in a pathway to form cholesterol (5) (Figure 1), as well as the 7,8 bond in 7,8-dehydrodesmosterol to form desmosterol (a sterol that is relatively abundant in the brain). A major biochemical consequence of defective DHCR7 in SLOS patients is an accumulation of 7-DHC in plasma and tissues of patients, and likely 7,8-dehydrodesmosterol in the brain. 7-DHC isomerizes to form 8-DHC (cholesta-5,8(9)-dien-3 $\beta$-ol), that is also found in large excess in SLOS. Accumulation of DHC is utilized in the diagnosis of SLOS, which is performed primarily by measurement of elevated plasma 7-DHC (2.7-470 ug/ml; 10-2000 fold normal) in the proper clinical setting. For prenatal diagnosis an increased concentration of 7-DHC in amniotic fluid after the $14^{\text {th }}$ week of gestation (33-35) or in chorionic villus samples between the $10-12^{\text {th }}$ week of gestation $(36 ; 37)$ is confirmatory for SLOS. Sampling of chorionic villus carries a risk of spontaneous abortion that limits its usefulness.

\section{Steroids in SLOS}

As cholesterol is a precursor to adrenal hormones, insufficient synthesis of adrenal steroid hormones may be expected in SLOS, and indeed adrenal insufficiency has been identified as a treatable manifestation that can occur in SLOS (38).

In addition, un-saturated analogues of pregnenolone, pregnanetriol, dehydroepiandrosterone and androstenediol derived from 7- and 8-DHC, have been detected in SLOS patient urine (39). A urinary steroid sulfate with a proposed keto-pregnadien-diol structure was also detected in patient urine (40). 7-dehydroallopregpregnanolone, a $\Delta 7$ un-saturated analogue of the neurosteroid allopregpregnanolone, was also identified in SLOS patient urine (41).

In human pregnancies with DHCR7 deficient fetuses adrenal 7- and 8-DHC are precursors for steroid synthesis in the fetus, and significant amounts of $\Delta 7$ and $\Delta 8$ un-saturated $\mathrm{C}_{18}$, $\mathrm{C}_{19}$ and $\mathrm{C}_{21}$ dehydrosteroids are excreted in maternal urine once the fetal adrenal gland becomes active at 10-11 weeks gestation (42-44). In a large multi-center trial, measurement of maternal urinary dehydroestriol, 7-dehydropregnanetriol or 8-dehydropregnanetriol (expressed as ratios to naturally occurring estriol and pregnanetriol) could be used as a noninvasive prenatal test for SLOS between 14 and 22 weeks of gestation (43).

\section{Bile acids in SLOS}

As bile acids are synthesized from cholesterol, overall bile acid deficiency may also be present SLOS. Fecal bile acids were virtually absent in 6 month old girl affected with a severe SLOS phenotype (6), however after cholesterol supplementation in this subject normal amounts of primary bile acids were excreted in bile and feces (45). In another study no difference in bile acid synthesis, as measured by the sterol balance technique that quantifies fecal sterols and bile acids, was found in SLOS and control subjects subjected to a controlled diet low in cholesterol (46). Overall, bile acid deficiency may not be a feature of SLOS, except in the most severely affected patients; further research is needed.

Unusual bile acids derived from DHC have been characterized in SLOS patients. Fast Atom Bombardment- and GC-MS analysis of urine from SLOS patients indicated deficiency in bile acids (cholanoic acids) and the presence of abnormal species, postulated to be hydroxylated cholenoic and cholestenoic acid sulfates $(47 ; 48)$. In experiments using rat liver tissue, 7- and 8-DHC were found to be competitive inhibitors of the cholesterol 7ahydroxylase and sterol 27-hydroxylase enzymes (49) that initiate bile acid synthesis (Figure 1). As substrates for the sterol 27 -hydroxylase, they were partially converted to $3 \beta$ hydroxycholestandienoic acids (49). These results suggest reduced bile acids in some SLOS 
patients may be a result of competitive inhibition of cholesterol 7a-hydroxylase and sterol 27-hydroxylase enzymes, in addition to lack of cholesterol.

\section{DHC-derived sterols \& oxysterols}

7-DHC can undergo lipid peroxidation and maintain an oxidative free radical chain reaction at a very high rate (21). It is possible oxidatively derived DHC sterols and oxysterols that are formed in SLOS play a role in disease pathophysiology. For example, UV photosensitivity is a common phenomena in SLOS (50), and in keratinocytes UV photosensitivity is likely a result of oxidative stress generated by 7-DHC (51) or 7-DHC derived metabolites, for example cholesta-5,7,9(11)-trien-3 $\beta$-ol (22;23). The AY9944-induced rat SLOS model has been shown to be hypersensitive to intense light-induced retinal damage (52). In this model, generation of cytotoxic oxysterols from 7-DHC oxidation was proposed to be an integral part of retinal cell death exacerbated by intense light, with antioxidant therapy demonstrating possible ameliorative effects (52).

Enzyme-catalyzed formation of atypical DHC derived oxysterols can also occur in SLOS; 27-hydroxylated 7- and 8-DHC have been detected in serum from SLOS patients (53) (Figure 1). In addition, levels of oxysterols derived from cholesterol may be altered in SLOS. Bjorkhem and colleagues demonstrated that 24S-hydroxycholesterol, a circulating marker of cholesterol synthesis in the brain, was markedly reduced in plasma from SLOS patients (54). Curiously, although 7-DHC is a precursor in the cutaneous synthesis of vitamin $\mathrm{D}$, circulating concentrations of vitamin $\mathrm{D}$ metabolites were not found to be significantly different from concentrations in appropriate controls (55).

\section{Novel Bioanalytical Approaches to SLOS testing}

Although GC-MS has long provided a sensitive and broad method for sterol detection, and has become an established method for diagnostic confirmation of SLOS, LC-MS methods have also been explored (56). More recently LC-tandem mass spectrometry (MS/MS) methods have been described for the selective detection of SLOS associated sterols that offer good sensitivity, faster run times, and sample-processing and analysis more amenable to automation and high-throughput sample testing (40). Sterol derivatization strategies in particular have been utilized to improve ESI-MS/MS method sensitivity, enabling detection of DHC and cholesterol from small volumes of amniotic fluid (57), serum and plasma (58;59). These methods demonstrate potential for population-based dried blood spot (DBS) screening for SLOS as DHC and cholesterol can be extracted and analyzed from DBS (57) or dried plasma spots (59). An emerging surface sampling/ionization technique; atmospheric pressure thermal desorption chemical ionization has been recently used for MS analysis of DHC and cholesterol directly from DBS obtained from SLOS patients (60).

\section{Clinical Phenotype of SLOS}

SLOS is characterized by multiple congenital malformations, intellectual disability and behavioral disorders. Typical craniofacial features include microcephaly, bitemporal narrowing, ptosis, short nasal root, anteverted nares and micrognathia (Figure 2, Part A). A majority of patients have 2,3-toe syndactyly (Figure 2, Part B). Table 1 demonstrates other clinical features of the syndrome $(19 ; 24)$. Initially, two phenotypes of SLOS were described, type I being milder and type II more severe. However, after discovery of the biochemical defect, both were recognized to fall within the clinical spectrum of the same disorder. Severely affected SLOS infants with major organ malformations often die in the perinatal period. Among survivors, there is great variability in phenotypic expression with some individuals exhibiting a milder phenotype (Figure 2, Part C), while others have malformations in virtually every organ system. At the mildest end of the spectrum, some 
children with SLOS have been identified with borderline normal IQ (personal observation $R D S)$.

The majority of SLOS individuals have global intellectual disability $(24 ; 61 ; 62)$. Although moderate to severe cognitive disability is typical, approximately $10 \%$ of children have mild retardation, and a few have normal or borderline normal development (63). The spectrum of psychomotor development in SLOS may change due to increased recognition of milder phenotypes in the future.

Feeding problems and failure to thrive are common in newborns and infants with SLOS due to weak suckling, swallowing difficulties, vomiting and lack of interest in food $(24 ; 27)$. Weight gain is poor during the initial years, many patients require tube feedings, often necessitating gastrostomy placement. Hypotonia is nearly universal in infancy, however muscle tone improves with age (27). Gross motor development is more delayed than fine motor skills, however most children eventually learn to walk.

Behavioral features of SLOS includes sleep disturbances, irritability, repetitive and ritualistic behaviors, aggressiveness, self injury activity, social and communication impairment, attention deficit hyperactivity disorder, and autism spectrum disorder (64). Sleep disturbances vary with age. While parents report excessive sleepiness in young infants, insomnia is more common in older children and tends to diminish with age (24). SLOS infants are often irritable and have prolonged, inconsolable screaming episodes. Aggressive and self injurious behaviors have been reported in up to $60 \%$ and $90 \%$ of children and adults with SLOS respectively $(24 ; 64)$.

\section{Recent Behavioral Insights in SLOS}

Behavioral abnormalities that fall within the spectrum of autistic disorder have frequently been reported in SLOS children. While the rate of autistic spectrum disorder (ASD) in general population is 1:91 (Kogan,M.D., Blumberg,S.J., Schieve,L.A., Boyle,C.A., Perrin,J.M., Ghandour,R.M., Singh,G.K., Strickland,B.B., Trevathan,E., van Dyck,P.C. 2009. Prevalence of parent-reported diagnosis of autism spectrum disorder among children in the US 2007, Pediatrics 124:1395-1403), Tierney et al found that 53\% patients with SLOS met the diagnostic criteria for ASD $(64 ; 65)$. Steiner et al reported a higher percentage (71-86\%) (66). The much higher rate of ASD in individuals with SLOS and the finding that cholesterol levels are below the 5th percentile in about $20 \%$ of children with ASD suggest a possible link between cholesterol and autism (67). Structural changes found in the central nervous system in small numbers of patients with autism suggest an insult causing autism can occur in utero in the first trimester, as early as 20-24 days after conception $(68 ; 69)$. Interestingly, treatment of pregnant rats with valproic acid, demonstrated to inhibit cholesterol synthesis in the rat brain during development (70), can induce experimental autism in offspring (Kuwagata M, Ogawa T, Shioda, S, nagata, T 2009 Int J Dev Neurosci 27(4): 399-405). This raises the possibility that valproic acid-induced autism may be mediated by cholesterol suppression and suggests the maternal and fetal cholesterol environment is a critical factor in the development of autism. One can further speculate, in addition to dietary cholesterol supplementation during pregnancy preventing embryomalformation and severe fetal hypocholesterolemia in a rat model of SLOS (115), cholesterol supplementation may also protect from ASD development in the offspring.

\section{Therapeutic Interventions}

Life expectancy in SLOS is determined primarily by the severity of internal malformations and quality of supportive care. Surgical interventions to repair congenital anomalies and gastrostomy placement to support nutritional status are often needed. Dietary cholesterol 
supplementation, although somewhat controversial, has become a standard potentially therapeutic intervention for individuals with SLOS. Initial protocols suggested cholesterol "doses" ranging from $20 \mathrm{mg} / \mathrm{kg} / \mathrm{day}$ up to $300 \mathrm{mg} / \mathrm{kg} / \mathrm{day}$, either in natural form (eggs, cream, liver, meats) or as purified food grade cholesterol sprinkled on food, in oil, or in aqueous solution (27). The estimated cholesterol supplementation during infancy is 30-40 $\mathrm{mg} / \mathrm{kg} /$ day (46). Cholesterol supplementation, in addition to providing cholesterol to tissues, down-regulates HMG-CoA reductase activity and presumably suppresses 7-DHC synthesis $(25 ; 71)$. Although a few uncontrolled early human studies showed that cholesterol supplementation results in increased plasma cholesterol concentration $(45 ; 61 ; 72)$, and positive behavioral and affective changes in SLOS patients $(62 ; 64 ; 73)$, others have reported that cholesterol supplementation does not improve the developmental progress of children and adolescents with SLOS (74;75). Although cholesterol supplementation may increase plasma cholesterol concentrations and potentially ameliorate the extra-CNS phenotype of SLOS, including improvement in photosensitivity (76;77), plasma cholesterol in the circulation does not cross the blood-brain-barrier. Therefore beneficial effects on brain 7 DHC synthesis and brain cholesterol content are unlikely.

Statin medications, routinely used to treat hypercholesterolemia by inhibiting HMG-CoA reductase, have also been evaluated in preliminary studies in SLOS, to reduce accumulation of 7-DHC and 8-DHC (78-80). Simvastatin crosses the blood brain barrier (81), and by potentially reducing brain 7-DHC and 8-DHC, has the potential to improve neurological and cognitive outcomes. However, statins may also reduce cholesterol, an unwelcome effect in SLOS. The statin treatments to date have typically provided statins in addition to cholesterol supplementation $(80 ; 82)$ or statins plus fresh frozen plasma as a source of cholesterol (78). Jira et al reported that long-term treatment of two SLOS patients with simvastatin, preceded by exchange transfusion, was associated with long-lasting improvement of the 7-DHC-tocholesterol ratio in plasma and in cerebrospinal fluid. Haas et al (80) reported the results of a retrospective study with simvastatin in 39 SLOS patients, which revealed that cholesterol supplementation in combination with simvastatin decreased the plasma (7-DHC + 8-DHC)/ cholesterol ratio, a ratio considered as a severity index of the disease, but improvement in growth and behavior could not be confirmed.

Porter et al (83) reported the results of simvastatin treatment of SLOS fibroblasts with residual DHCR7 enzymatic activity. This study showed decreased 7-DHC concentrations and increased cholesterol synthesis hypothesized to occur by increased expression of the mutant allele with residual function (HMG-CoA inhibition induces a concerted upregulation of the majority of enzymes required for cholesterol synthesis). Correa-Cerro et al (14) also studied the effect of simvastatin on hypomorphic $D h c r 7^{T 93 \mathrm{M} / \Delta 3-5}$ mice and found that simvastatin decreased 7-DHC concentrations in both peripheral and brain tissues, while increasing the expression of Dhcr 7 in tissues, (14).

Caution is advised when administering statins in SLOS, as statins reduce plasma 24Shydroxycholesterol concentrations in non-SLOS subjects (84), suggesting a reduction in brain cholesterol synthesis. Whether statins reduce cholesterol synthesis in SLOS subjects needs to be confirmed with further studies. Marked elevations in transaminases and creatine kinase have been reported in patients more severely affected with SLOS (79). Controlled, long-term studies in SLOS patients are needed to evaluate the efficacy and safety of simvastatin in SLOS.

\section{Novel Therapeutic Approaches}

Watson and colleagues recently described restoring DHCR7 activity in $D h c r 7^{\Delta{ }^{\wedge-5}}$ mice ( $D h c r 7$ null) liver by treatment with adenovirus-associated viral (AAV) vector containing 
the human DHCR7gene (85). Preliminary data showed improvement in the DHC/ cholesterol ratio. If effective in humans, this approach might offer a possible alternative to exogeneous cholesterol therapy, however, a complete cure is not possible as consequences of the genetic defect are already established during prenatal development. Modulation of maternal-fetal cholesterol transport has the potential for in utero treatment of SLOS. Lindegaard et al showed that Abca1, a cholesterol transporter in placenta, contributes to transport of maternal cholesterol to the developing fetus, and in a SLOS mouse model, in utero treatment with TO901317, an LXR-agonist that induces Abca1, increased cholesterol content in $\mathrm{Dhcr} \mathrm{T}^{-1-}$ embryos (86). Irons et al (87) reported on the effect of antenatal cholesterol supplementation via fetal intravenous and intraperitoneal transfusions of fresh frozen plasma. The in utero transfusions resulted in increased levels of fetal cholesterol, as measured in blood samples obtained by cordocentesis.

\section{Genotype in SLOS}

The gene, DHCR7, maps to chromosomal region 11q13. SLOS genomic DNA covers about 14,000 base pairs; 7 of the 9 exons (exons 3 through 9 ) code for the protein. The mRNA contains 2786 nucleotides with a 1425 bases of open reading frame that codes for 475 amino acids. The transcripts are ubiquitously expressed with the highest mRNA concentrations in adrenal gland, liver, testes and brain (8). A recent review describes several potential regulatory elements in the 5' untranslated region: three SP1 sites, an inverted NF-Y site, and a potential partial SRE1/E -box (88). Expression of DHCR $7 \mathrm{mRNA}$ is induced in rats on a diet designed to decrease cholesterol absorption and synthesis (chow with cholestyramine and lovastatin) (89). Alternative splicing in the 5'UTR of the rat Dhcr 7 creates 5 isoforms (90). The isoforms are differentially expressed in different tissues and at different ages, suggesting potential regulatory function. In one human liver cell line, however, only one RNA species was identified.

The enzyme synthesized from the coding region is DHCR7 (E.C. 1.3.1.21) with a predicted sequence of 475 amino acids and a predicted molecular weight of about 55,000 kDa. DHCR7 catalyzes the conversion of 7-DHC to cholesterol and 7-dehydrodesmosterol to desmosterol requiring NADPH (91). The human amino acid sequence has 56\% identity to the plant enzyme (A.thaliana.), $87 \%$ identity to the rat enzyme (92) and $89 \%$ identity to the mouse enzyme (9). Commercial antibodies to DHCR7 are not currently available, hampering the study of protein expression. A putative sterol sensing domain has been predicted in the rat enzyme, amino acid residues 177-358, corresponding to 181-362 in the human protein (92). There is a sterol reductase 1 motif (amino acids 213-228), a sterol reductase 2 motif (amino acids 439-462), and a sterol reductase signature motif (amino acids 394-405) (88) (Figure 3).

In tissue culture, 7-DHC provides negative feedback to HMG CoA reductase, the enzyme thought normally to be the rate limiting enzyme for cholesterol synthesis (93). The enzyme is located in the microsomal fraction. Although, the three dimensional structure is unknown, it is predicted to have 9 transmembrane spanning domains (9;94)(Figure 3). Measurement of enzyme activity is difficult due to the lack of commercially available isotopically labeled 7DHC. Several labs have measured activity using different strategies including: (1) synthesizing the isotopically labeled 7-DHC in the lab and measuring the conversion to cholesterol (95), (2) measuring the conversion of a plant sterol ergosterol, to brassicasterol (96), and (3) measuring the conversion of $\mathrm{D}_{2} \mathrm{O}$ to deuterium labeled 7-DHC and cholesterol and expressed as the fractional cholesterol synthesis cholesterol/(cholesterol + 7-DHC) (83). Very low enzyme activity is measured in patient fibroblasts compared with controls (95). 
Since the first mutations in $D H C R 7$ were reported in individuals with SLOS $(9 ; 10 ; 94)$, over 100 different mutations have been described in the literature, in addition to at least 15 variants that likely do not cause disease (29). Most of the mutations are missense, although one of the most common mutations is a splice site mutation (described below). Affected individuals generally are compound heterozygotes with a different mutation in each allele. Of the 32 subjects followed in our study, only one is homozygous. Multiple phenotypes, ranging from very mild to very severe, result from a large number of different combinations of mutations. A small number of mutations have been labeled "null mutations" producing an enzyme with no activity predicted. These are the splice mutation c.964-1G>C (also described as IVS8-1G>C) and the nonsense mutations: p.E37X, p.Q98X, and p.W151X. Patients with combinations of these null mutations are very severely affected, often not surviving the neonatal period, but those with c.964-1G $>C$ homozygous null mutations have detectable concentrations of cholesterol. This splice mutation may be leaky, providing some properly spliced enzyme with full activity. Several groups of patients have a null mutation combined with another mutation: p.T93M, p.V326L, p.R352W and p.R404C. One would expect that the severity would be due to the second allele, but there is wide variability of clinical severity within each group (88). This suggests that there are factors in addition to the SLOS genotype that significantly influence the clinical severity. Other genes involved in cholesterol synthesis, transport or regulation are likely to modify outcomes, for example, (1) differences in the conversion of 7-DHC to abnormal steroids, oxysterols or neuroactive sterols, (2) the supply of cholesterol during development regulated by the activity of the ABCA1 cholesterol transporter (86), (3) maternal ApoE genotype that affects cholesterol transfer from the mother to the fetus (97), or (4) the size of the HDL particles (smaller size in cord blood from affected fetus than in controls) that may influence the transport of maternal cholesterol to the fetus (98). Occasionally, only one mutation has been found in the coding region and around the splice sites of the exons. We hypothesize that the missing mutation could be in the untranslated regulatory region, in a section of an intron with a vital function that has not yet been identified or perhaps as a deletion too big to be identified by sequencing. Two mutations have been found in all but one of the patients in which the $D H C R 7$ gene has been sequenced by our research laboratory.

Estimates of incidence range from 1:80:000 (99) to 1:13,000 (100;101). Undiagnosed fetal loss, difficulty in identifying mild cases, and missed diagnosis of very severe cases where likely the diagnosis may be determined to be brain malformation make the true determination of incidence difficult. The most common mutations are p.T93M, p.W151X, p.V326L, p.R352W, p.R404C, p.E448K and c.964-1G >C. The frequency of c.964G>C and $\mathrm{W} 151 \mathrm{X}$ mutations depends on the geographic region. The c.964-1 G>C mutation is most frequent in North America and Western Europe (102). The p.W151X mutation is most frequent in Central and Eastern Europe (103;104). This suggests a founder effect for these 2 mutations. Fifty percent of the mutations occur in transmembrane regions. A selective advantage for heterozygotes has been proposed, in an effort to explain the high incidence of SLOS. Increased 7-DHC concentrations may increase vitamin D synthesis and may lower the risk of rickets (27). Perhaps low cholesterol concentrations in tissues provides protection from infection, because cholesterol in the cell membrane is a crucial component required by microorganisms, to enter and/or exit the cells. In addition, cholesterol is necessary for cytolytic activity of cholesterol-dependent cytolysins (105).

\section{Mutation analysis}

In most cases the biochemical test, measurement of 7-DHC and cholesterol concentrations in plasma, is the simplest and most convenient method for diagnosis. It is important to note that plasma cholesterol concentrations can be in the normal range in SLOS, so normal plasma cholesterol by no means rules out the diagnosis of SLOS. In at least 2 situations mutation 
analysis may be necessary or at least very useful: borderline concentrations of 7-DHC and prenatal testing. Some mildly affected children with SLOS can have 7-DHC as low as 0.1 $\mathrm{mg} / \mathrm{dL}$ (106), and occasionally children who lack DHCR7 mutations can have elevated 7DHC, greater than $0.1 \mathrm{mg} / \mathrm{dL}$ (those with other disorders, for example, the bile acid synthesis disorder cerebrotendinous xanthomatosis), although virtually every individual with diagnostically elevated 7-DHC in the proper clinical setting is affected with SLOS. In families with a known genotype, prenatal diagnosis of SLOS by mutation analysis of chorionic villus samples or amniotic fluid cells can be performed (107). Testing of maternal urine for abnormal sterols synthesized by the fetus has also been shown to be accurate and is less invasive (108). Preimplanatation genetic diagnosis is reported in 2 cases with the transfer of mutation-free embryos and successful pregnancies (109).

Attempts have been made to develop animal models for SLOS to elucidate the biochemical and cellular basis for the pathophysiology of the syndrome and provide a basis to develop and test potential dietary, pharmacologic, and other treatments. The attempt is challenging because the SLOS subjects suffer both physical and psychological abnormalities, and because cholesterol is vital to normal development.

\section{Animal models of SLOS treated with DHCR7 inhibitors}

The malformations seen in rats treated with DHCR7 inhibitors overlap with those seen in human SLOS subjects. AY9944 (trans-1,4-bis(2-chlorobenzyl-amino-methyl)cyclohexane dihydrochloride) and BM15766 (4-(1-(4-chlorocinnamyl)piperazin-4-yl)ethyl)-benzoicacid) are chemically unrelated inhibitors of DHCR7, but they induce similar defects in off spring when fed to pregnant rats at different time points during gestation (110-112). When AY9944 is given to rats on gestation day 3, the offspring develop holoprosencephaly, when given on day 10, male offspring develop sexual malformations. If the maternal plasma cholesterol concentrations during pregnancy are below $30 \mathrm{mg} / \mathrm{dL}$, the malformation of rat fetus is holoprosencephaly (112). BM15766 has teratogenic potency similar to AY9944. Wolf et al studied changes in serum sterols of rats treated with these inhibitors and compared sterol concentrations in the model and in humans with SLOS (113). Both drugs lower plasma cholesterol concentrations and elevate plasma 7-DHC concentrations. The aberrant sterols detected in rats are similar to those observed in human SLOS subjects. They include 7-DHC and 8-DHC. Gaoua et al showed that oxidized derivatives of 7-DHC induce growth retardation in cultured rat embryos suggesting a toxic role for 7-DHC and derivatives (114). Fliesler et al showed retinal degeneration in rats treated with AY9944 comparable to those observed in the human disease (16). However, there appear to be a number of differences between pharmacologic animal models and humans with SLOS. Pharmacologic inhibition is reversible and is species dependent. For example Westar rats are more sensitive to the tetratogenic action of AY9944 as compared to Sprague-dawley rats, and mice are more resistant than rats, requiring 10-20 times the rat dose (116). Three distal inhibitors of cholesterol synthesis, AY9944, BM15766 and triparanol, have different chemical structures, different physical properties (and triparanol a different target enzyme), but have similar teratogenic activity. Gaoua et al suggested that deficiency of cholesterol and not accumulation of aberrant sterols is the major cause of teratogenic activity in SLOS animal models (117). Careful consideration of physiological cholesterol differences, and maternalfetal sterol transfer, between and among the different rat and mice strains may help us better understand malformation development in utero in SLOS. In rat models, cholesterol supplementation to mothers prevents embryo malformation, severe hypocholesterolemia and accumulation of abnormal sterols (115). Fetal cholesterol is thought to be low during embryogenesis with malformations occurring in tissues and structures whose embryonic patterning depends on signaling by the Hedgehog family of secreted proteins, after these proteins are activated by cholesterol. Insufficient cholesterol, however, is an overly 
simplistic explanation. Cooper et al showed in studies using chick embryos, chick neural plate explants, and in cultured fibroblasts that malformations in SLOS are not likely due to sterol depletion and altered hedgehog activation, since 27-carbon cholesterol precursors including 7-DHC and lathosterol can substitute for cholesterol in sonic hedgehog activation but rather to signaling defects in the Patched and Smoothened pathways (18). In addition, Krakowiak et al (Lathosterolosis: an inborn error of human and murine cholesterol synthesis due to lathosterol 5-desaturase deficiency, Krakowiak PA, Wassif CA, Kratz L, Cozma D, Kovárová M, Harris G, Grinberg A, Yang Y, Hunter AG, Tsokos M, Kelley RI, Porter FD., Hum Mol Genet. 2003 Jul 1;12(13):1631-41) showed that hedgehog signaling is impaired in embryonic fibroblasts derived from the Sc5d (lathosterolosis) mutant mouse, suggesting impairments in Smoothened and Patched signaling, rather than defective hedgehog activation are likely responsible for the malformations in SLOS.

\section{Genetic Mouse models for SLOS}

Wassif et al generated a genetic mouse model by disrupting the mouse $D h c r 7$ gene in mouse embryonic stem cells by targeted homologous recombination (12). Heterozygous mice appeared phenotypically normal. Homozygous pups died during their first day of life as a result of their failure to feed. Homozygous pups were growth retarded, had craniofacial abnormalities such as cleft palate, and failed to feed due to an inability to suck. The lack of suckling combined with decreased movement observed in these homozygous pups are similar traits to those observed in some severely affected SLOS children and may be attributed to neurological abnormalities. The SLOS mouse had low plasma cholesterol concentrations and elevated plasma 7-DHC levels. In homozygous pups, serum levels of 7DHC were increased $>1500$ fold and tissue levels by 250-2000 fold as compared to controls. In the central nervous system of mutant mice desmosterol levels were reduced drastically and7-DHC levels were similar to cholesterol levels. Fitzky et al created a SLOS mouse model by mutating $D h c r 7$ gene by homologous recombination (13). The homozygous pups showed low brain and liver cholesterol concentrations and 30-40 fold elevated concentrations of 7-DHC, however the new born pups did not suckle, had cleft palate and immature lungs, and died within 18 hours after birth. Cholesterol deficits were most profound in the brain with DHC composing $80 \%$ of total sterols. Desmosterol not detected, with 7-dehydrodesmosterol accumulating, due to lack of 7,8-reductase activity (13).

The fact that these SLOS models do not survive for more than a day, suggests that we need a better model to study alterations neurophysiological functions in SLOS subjects. CorreaCorro et al produced a hypomorphic mouse model by introducing a mutation corresponding to the p.T93M mutation found in SLOS patients. Both $D h c r 7^{793 \mathrm{M} / \mathrm{T} 93 \mathrm{M}}$ and $D h c r 7^{193 \mathrm{M} / \Delta 3-5}$ mice were viable, fertile and had high7-DHC concentrations (14). Dher $7^{\text {T93M/T93M }}$ appeared normal while $D h c r 7^{793 \mathrm{M} / \Delta 3-5}$ demonstrated mild growth retardation, syndactyly, and occasional cleft palate. In these pups, the sterol defect in peripheral tissues improved with age.

\section{Insights provided by SLOS mice}

Simvastatin treatment reduced 7-DHC concentrations in peripheral tissues and in CNS tissues of $D h c r 7^{7 \mathrm{~T} 93 \mathrm{M} / \Delta 3-5}$ pups. Correa-Corro et al concluded that simvastatin treatment may be effective in improving brain sterol profile and effectively treat behavioral and learning problems in SLOS subjects (14). Marcos et al further characterized cholesterol metabolism in pups with emphasis on changes during first few weeks of post natal development (118). In perinatal to weanling age SLOS mice, cholesterol and 7-DHC concentrations changed, changes in brain and liver were independent. However using age matched animals at early ages, may provide an insight into the mechanism in these mice to 
normalize cholesterol. The viability of these animals have enabled Patti et al to provide images of brain sterol localization in the abnormally developing cerebellum and brainstem of Dhcr $\lambda^{-/-)}$mice using in situ detection of molecules from brain tissues with cationenhanced nanostructure-initiator MS (119).

\section{Future research directions}

It is notable that the biochemical basis for SLOS has been understood for over 15 years, and the molecular genetic basis for over 10 years, and yet there is still no proven therapy. One of the most important goals for continued research in SLOS should be development of better animal models. The current rodent models are suboptimal because of lethality in once case (12), reversion to normal in a second (14), and non-specificity stemming from pharmacologic treatment in a third. Yu et al have introduced liver and CNS DHCR7 trangenes into the KO mouse model $(120 ; 121)$. Selective reconstitution of liver cholesterol biosynthesis promotes lung maturation but does not prevent neonatal lethality in Dhcr 7 null mice (120). Limited success was obtained in rescuing the neonatal lethality with a brain $D H C R 7$ transgene (121). However, tissue-specific transgenic, conditional Dhcr 7 knockout and knock-in mice are needed to allow further studies of pathophysiology and to test interventions in animal models before moving to humans.

In addition to animal models, creation of cellular models of human SLOS will surely be useful. For example, creation of SLOS induced pluripotent stem cells, (iPS) would allow various SLOS cell types to be grown in culture and studied. Human brain derived cells or neural iPS are urgently needed, for studying the pathophysiology of SLOS and for testing the effect of interventions on the cells that must be targeted if therapy is to have a significant effect in SLOS. In order for brain derived stem cells to become available, courageous families will need to donate brain tissue from their precious children when they die; already the Smith-Lemli Opitz/RSH Foundation (http://www.smithlemliopitz.org/) has teamed up with the National Disease Research Interchange (http://www.ndriresource.org/) to facilitate such donations.

Proteomic and lipidomic approaches are already yielding insights into SLOS. Porter and colleagues recently identified differentially expressed proteins in SLOS KO mouse brain (122). Identification of increased cofilin-1 expression led to the finding of aberrant activation of Rho/Rac signaling in SLOS that could have functional consequences for dendrite and axonal growth. Associated with this, were developmental abnormalities of neuronal process formation, that may contribute to the neurocognitive deficits found in SLOS. The authors speculated that this may represent a potential target for therapeutic intervention. At a minimum, these findings should be followed up with additional investigation of aberrant signaling pathways in SLOS. Few published lipidomics studies in SLOS are available; Fliesler and colleages studied lipid expression in the retina of the pharmacologic SLOS rat model (123). These investigators found that the retinal lipidome is globally altered in the SLOS rat model, with the most profound changes being less phosphatidylcholine, phosphatidylethanolamine, and phosphatidylserine molecular species containing docosahexaenoic acid $(22: 6)(123 ; 124)$. Additional lipidomic studies in SLOS are warranted, perhaps using the SLOS mouse models and available human tissues as well, to see if these findings are confirmed. Further specific investigation into phospholpid and fatty acid metabolism in SLOS is also likely to be illuminating, as the cholesterol deficit and dehydrocholesterol excess clearly have many secondary effects that contribute to disease pathophysiology.

In vitro studies, and use of animal models will undoubtedly move the field forward, but in vivo human studies are critical as well. There have only been limited phenotypic and natural 
history studies of SLOS to date. More comprehensive studies of natural history and targeted studies following up on earlier observations are ongoing. For example, Irons and colleagues reported in a study of brain MRI and MRS in SLOS that the choline:NAA (N-

acetylaspartate), lipid:NAA ratios and lipid:choline metabolites were found to be correlated with the clinical disease severity, serum sterols, and in two cases with the effect of cholesterol supplementation (125). 1H MRS demonstrated abnormally elevated lipids prior to cholesterol therapy, which improved with dietary cholesterol (125). Brain 1H MRS may yield biomarkers useful for the assessment of the effects of interventions in SLOS in the brain. This and additional biomarker development will be critical in facilitating clinical trials in this rare condition, since clinical phenotype may change slowly over many years.

Methods are needed for determining brain and whole body cholesterol mass and accretion, and the effects on interventions on these parameters.

Finally, development and testing of additional potential therapies will be absolutely critical if we are to make headway toward ameloriating the effects of this condition. Approaches such as mechanical delivery of cholesterol to the brain should be considered. The blood brain barrier represents a major obstacle to treatment of SLOS. Potential areas of investigation to overcome this obstacle are (1) bypassing the blood brain barrier by direct injection of cholesterol to the brain, (2) developing synthetic sterols that can cross the blood brain barrier, (3) transplanting neural stem cells into the brain and/or (4) delivering cholesterol from the peripheral circulation by disrupting the blood brain barrier (126). Gene transfer techniques are perhaps the most promising, considering recent successes in gene therapy for neuologic disorders (127), though still years away from human clinical trials SLOS. Still, recent progress in gene transfer studies in animal models for SLOS are exciting progress (85). If maximal benefit of therapeutic approaches is to be realized, prenatal approaches to therapy may be necessary. Steps as simple as cholesterol supplementation early in pregnancy in mothers at risk for carrying an SLOS fetus may be worthy of investigation, given what we know about maternal-fetal transfer of cholesterol $(98 ; 128)$. Additional investigations into origins of fetal and embryonic cholesterol and prenatal cholesterol transport are ongoing, but almost exclusively in animals: creative thinking is needed to explore this difficult to study issue in humans. More practical, closer at hand therapies, also warrant investigation. The bile acids, ursodeoxycholic acid and chenodeoxycholic acid have been used in early trials of cholesterol supplementation in SLOS to ameliorate potential bile acid deficiency and improve cholesterol absorption $(61 ; 129)$ and are still used in certain situations. Recently, tauroursodeoxycholic acid (TUDCA), a taurine-conjugated bile acid with antioxidant, anti-apoptotic, and neuroprotective properties, has been investigated as a therapy for other disorders. Evidence that TUDCA crosses the blood brain barrier (130), 1991), makes TUDCA a potential therapy for SLOS. There is also evidence of increased oxidative stress in SLOS (21), suggesting that investigation of the safety and efficacy of antioxidants in SLOS may be warranted, especially given the good safety record of many antioxidants.

\section{Acknowledgments}

The Steiner laboratory is supported by a grant from the US Public Health Service; R01 HL073980 and by a cooperative agreement (U54 HD061939) for the Sterol and Isoprenoid Diseases (STAIR) consortium, part of the NIH Rare Diseases Clinical Research Network (RDCRN) supported by NICHD and the NIH Office of Rare Diseases Research (ORDR). This work was also supported by a Training grant awarded to A.E.D. from the Sterol and Isoprenoid Diseases (STAIR) consortium. In addition, we gratefully acknowledge J Roullet and J Adsit for help in preparing the manuscript, and the anonymous peer reviewers for insightful review of the manuscript and constructive suggestions. 


\section{Reference List}

1. Smith DW, Lemli L, Opitz JM. A newly recognized syndrome of multiple congenital anomalies. J. Pediatr. 1964; 64:210-217. [PubMed: 14119520]

2. Opitz JM, Zellweger H, Shannon WR, Ptacek LJ. The RSH Syndrome. Birth Defects. 1969; 2:4352.

3. Dallaire L. Syndrome of retardation with urogenital and skeletal anomalies (Smith-Lemli-Opitz Syndrome): clinical features and mode of inheritance. J Med. Genet. 1969; 6:113-120. [PubMed: 4389828]

4. Irons M, Elias ER, Salen G, Tint GS, Batta AK. Defective cholesterol biosynthesis in Smith-LemliOpitz syndrome. Lancet. 1993; 341:1414. [PubMed: 7684480]

5. Kandutsch AA, Russell AE. Preputial gland tumor sterols. 3. A metabolic pathway from lanosterol to cholesterol. J. Biol. Chem. 1960; 235:2256-2261. [PubMed: 14404284]

6. Tint GS, Irons M, Elias ER, Batta AK, Frieden R, Chen TS, Salen G. Defective cholesterol biosynthesis associated with the Smith-Lemli-Opitz syndrome. N. Engl. J. Med. 1994; 330:107113. [PubMed: 8259166]

7. Shefer S, Salen G, Batta AK, Honda A, Tint GS, Irons M, Elias ER, Chen TC, Holick MF. Markedly inhibited 7-dehydrocholesterol-delta 7-reductase activity in liver microsomes from SmithLemli-Opitz homozygotes. J. Clin. Invest. 1995; 96:1779-1785. [PubMed: 7560069]

8. Moebius FF, Fitzky BU, Lee JN, Paik YK, Glossmann H. Molecular cloning and expression of the human delta7-sterol reductase. Proc. Natl. Acad. Sci. U. S. A. 1998; 95:1899-1902. [PubMed: 9465114]

9. Fitzky BU, Witsch-Baumgartner M, Erdel M, Lee JN, Paik YK, Glossmann H, Utermann G, Moebius FF. Mutations in the Delta7-sterol reductase gene in patients with the Smith-Lemli-Opitz syndrome. Proc. Natl. Acad. Sci. U. S. A. 1998; 95:8181-8186. [PubMed: 9653161]

10. Wassif CA, Maslen C, Kachilele-Linjewile S, Lin D, Linck LM, Connor WE, Steiner RD, Porter FD. Mutations in the human sterol delta7-reductase gene at 11q12-13 cause Smith-Lemli-Opitz syndrome. Am. J. Hum. Genet. 1998; 63:55-62. [PubMed: 9634533]

11. Waterham HR, Wijburg FA, Hennekam RC, Vreken P, Poll-The BT, Dorland L, Duran M, Jira PE, Smeitink JA, Wevers RA, Wanders RJ. Smith-Lemli-Opitz syndrome is caused by mutations in the 7-dehydrocholesterol reductase gene. Am. J. Hum. Genet. 1998; 63:329-338. [PubMed: 9683613]

12. Wassif CA, Zhu P, Kratz L, Krakowiak PA, Battaile KP, Weight FF, Grinberg A, Steiner RD, Nwokoro NA, Kelley RI, et al. Biochemical, phenotypic and neurophysiological characterization of a genetic mouse model of RSH/Smith--Lemli--Opitz syndrome. Hum. Mol. Genet. 2001; 10:555-564. [PubMed: 11230174]

13. Fitzky BU, Moebius FF, Asaoka H, Waage-Baudet H, Xu L, Xu G, Maeda N, Kluckman K, Hiller $\mathrm{S}, \mathrm{Yu} \mathrm{H}$, et al. 7-Dehydrocholesterol-dependent proteolysis of HMG-CoA reductase suppresses sterol biosynthesis in a mouse model of Smith-Lemli-Opitz/RSH syndrome. J. Clin. Invest. 2001; 108:905-915. [PubMed: 11560960]

14. Correa-Cerro LS, Wassif CA, Kratz L, Miller GF, Munasinghe JP, Grinberg A, Fliesler SJ, Porter FD. Development and characterization of a hypomorphic Smith-Lemli-Opitz syndrome mouse model and efficacy of simvastatin therapy. Hum. Mol. Genet. 2006; 15:839-851. [PubMed: 16446309]

15. Xu G, Salen G, Shefer S, Ness GC, Chen TS, Zhao Z, Tint GS. Reproducing abnormal cholesterol biosynthesis as seen in the Smith-Lemli-Opitz syndrome by inhibiting the conversion of 7dehydrocholesterol to cholesterol in rats. J. Clin. Invest. 1995; 95:76-81. [PubMed: 7814648]

16. Fliesler SJ, Peachey NS, Richards MJ, Nagel BA, Vaughan DK. Retinal degeneration in a rodent model of Smith-Lemli-Opitz syndrome: electrophysiologic, biochemical, and morphologic features. Arch. Ophthalmol. 2004; 122:1190-1200. [PubMed: 15302661]

17. Cunniff C, Kratz LE, Moser A, Natowicz MR, Kelley RI. Clinical and biochemical spectrum of patients with RSH/Smith-Lemli-Opitz syndrome and abnormal cholesterol metabolism. Am. J. Med. Genet. 1997; 68:263-269. [PubMed: 9024557] 
18. Cooper MK, Wassif CA, Krakowiak PA, Taipale J, Gong R, Kelley RI, Porter FD, Beachy PA. A defective response to Hedgehog signaling in disorders of cholesterol biosynthesis. Nat. Genet. 2003; 33:508-513. [PubMed: 12652302]

19. Porter FD, Herman GE. Malformation syndromes caused by disorders of cholesterol synthesis. J. Lipid Res. 2010; 52(1):6-34. [PubMed: 20929975]

20. Xu L, Korade Z, Porter NA. Oxysterols from free radical chain oxidation of 7-dehydrocholesterol: product and mechanistic studies. J. Am. Chem. Soc. 2010; 132:2222-2232. [PubMed: 20121089]

21. Korade Z, Xu L, Shelton R, Porter NA. Biological activities of 7-dehydrocholesterol-derived oxysterols: implications for Smith-Lemli-Opitz syndrome. J. Lipid Res. 2010; 51:3259-3269. [PubMed: 20702862]

22. Chignell CF, Kukielczak BM, Sik RH, Bilski PJ, He YY. Ultraviolet A sensitivity in Smith-LemliOpitz syndrome: Possible involvement of cholesta-5,7,9(11)-trien-3 beta-ol. Free Radic. Biol. Med. 2006; 41:339-346. [PubMed: 16814115]

23. De FE, Caruso D, Cavaleri M, Galli KM, Galli G. Cholesta-5,7,9(11)-trien-3 beta-ol found in plasma of patients with Smith-Lemli-Opitz syndrome indicates formation of sterol hydroperoxide. J. Lipid Res. 1996; 37:2280-2287. [PubMed: 8978479]

24. Ryan AK, Bartlett K, Clayton P, Eaton S, Mills L, Donnai D, Winter RM, Burn J. Smith-LemliOpitz syndrome: a variable clinical and biochemical phenotype. J. Med. Genet. 1998; 35:558-565. [PubMed: 9678700]

25. Ginat S, Maslen C, Connor WM, Porter FD, Steiner RD. Smith-Lemli-Opitz syndrome: A multiple malformation/mental retardation syndrome caused by defective cholesterol synthesis. The Endocrinologist. 2000; 10:300-313.

26. Porter FD. RSH/Smith-Lemli-Opitz syndrome: a multiple congenital anomaly/mental retardation syndrome due to an inborn error of cholesterol biosynthesis. Mol. Genet. Metab. 2000; 71:163174. [PubMed: 11001807]

27. Kelley RI, Hennekam RC. The Smith-Lemli-Opitz syndrome. J. Med. Genet. 2000; 37:321-335. [PubMed: 10807690]

28. Battaile KP, Steiner RD. Smith-Lemli-Opitz syndrome: the first malformation syndrome associated with defective cholesterol synthesis. Mol. Genet. Metab. 2000; 71:154-162. [PubMed: 11001806]

29. Yu H, Patel SB. Recent insights into the Smith-Lemli-Opitz syndrome. Clin. Genet. 2005; 68:383391. [PubMed: 16207203]

30. Porter FD. Smith-Lemli-Opitz syndrome: pathogenesis, diagnosis and management. Eur. J. Hum. Genet. 2008; 16:535-541. [PubMed: 18285838]

31. Phillipi, CA.; Steiner, RD. Disorders of Cholesterol Biosynthesis, Genetics of. In ENCYCLOPEDIA OF LIFE SCIENCES. John Wiley \& Sons,Ltd.; Chichester: 2008.

32. Steiner, RD.; Martin, LS.; Hume, RF. Smith Lemli Opitz syndrome. eMedicine from WebMD. Updated 2007. Available at <http://www.emedicine.com/ped/topiclist.htm>

33. Kelley RI. Diagnosis of Smith-Lemli-Opitz syndrome by gas chromatography/mass spectrometry of 7-dehydrocholesterol in plasma, amniotic fluid and cultured skin fibroblasts. Clin. Chim. Acta. 1995; 236:45-58. [PubMed: 7664465]

34. Kratz LE, Kelley RI. Prenatal diagnosis of the RSH/Smith-Lemli-Opitz syndrome. Am. J. Med. Genet. 1999; 82:376-381. [PubMed: 10069707]

35. Tint GS, Abuelo D, Till M, Cordier MP, Batta AK, Shefer S, Honda A, Honda M, Xu G, Irons M, et al. Fetal Smith-Lemli-Opitz syndrome can be detected accurately and reliably by measuring amniotic fluid dehydrocholesterols. Prenat. Diagn. 1998; 18:651-658. [PubMed: 9706645]

36. Nowaczyk MJ, Heshka T, Kratz LE, Kelley RE. Difficult prenatal diagnosis in mild Smith-LemliOpitz syndrome. Am. J. Med. Genet. 2000; 95:396-398. [PubMed: 11186897]

37. Linck LM, Hayflick SJ, Lin DS, Battaile KP, Ginat S, Burlingame T, Gibson KM, Honda M, Honda A, Salen G, et al. Fetal demise with Smith-Lemli-Opitz syndrome confirmed by tissue sterol analysis and the absence of measurable 7-dehydrocholesterol Delta(7)-reductase activity in chorionic villi. Prenat. Diagn. 2000; 20:238-240. [PubMed: 10719329]

38. Andersson HC, Frentz J, Martinez JE, Tuck-Muller CM, Bellizaire J. Adrenal insufficiency in Smith-Lemli-Opitz syndrome. Am. J. Med. Genet. 1999; 82:382-384. [PubMed: 10069708] 
39. Shackleton C, Roitman E, Guo LW, Wilson WK, Porter FD. Identification of 7(8) and 8(9) unsaturated adrenal steroid metabolites produced by patients with 7-dehydrosterol-delta7reductase deficiency (Smith-Lemli-Opitz syndrome). J. Steroid Biochem. Mol. Biol. 2002; 82:225-232. [PubMed: 12477489]

40. Pitt JJ. High-throughput urine screening for Smith-Lemli-Opitz syndrome and cerebrotendinous xanthomatosis using negative electrospray tandem mass spectrometry. Clin. Chim. Acta. 2007; 380:81-88. [PubMed: 17341417]

41. Marcos J, Guo LW, Wilson WK, Porter FD, Shackleton C. The implications of 7-dehydrosterol-7reductase deficiency (Smith-Lemli-Opitz syndrome) to neurosteroid production. Steroids. 2004; 69:51-60. [PubMed: 14715377]

42. Shackleton CH, Roitman E, Kratz L, Kelley R. Dehydro-oestriol and dehydropregnanetriol are candidate analytes for prenatal diagnosis of Smith-Lemli-Opitz syndrome. Prenat. Diagn. 2001; 21:207-212. [PubMed: 11260610]

43. Shackleton CH, Marcos J, Palomaki GE, Craig WY, Kelley RI, Kratz LE, Haddow JE. Dehydrosteroid measurements in maternal urine or serum for the prenatal diagnosis of SmithLemli-Opitz syndrome (SLOS). Am. J. Med. Genet. A. 2007; 143A:2129-2136. [PubMed: 17702049]

44. Matabosch X, Rahman M, Hughes B, Patel SB, Watson G, Shackleton C. Steroid production and excretion by the pregnant mouse, particularly in relation to pregnancies with fetuses deficient in Delta7-sterol reductase (Dhcr7), the enzyme associated with Smith-Lemli-Opitz syndrome. J. Steroid Biochem. Mol. Biol. 2009; 116:61-70. [PubMed: 19406241]

45. Irons M, Elias ER, Tint GS, Salen G, Frieden R, Buie TM, Ampola M. Abnormal cholesterol metabolism in the Smith-Lemli-Opitz syndrome: report of clinical and biochemical findings in four patients and treatment in one patient. Am. J. Med. Genet. 1994; 50:347-352. [PubMed: 8209913]

46. Steiner RD, Linck LM, Flavell DP, Lin DS, Connor WE. Sterol balance in the Smith-Lemli-Opitz syndrome. Reduction in whole body cholesterol synthesis and normal bile acid production. J. Lipid Res. 2000; 41:1437-1447. [PubMed: 10974051]

47. Natowicz MR, Evans JE. Abnormal bile acids in the Smith-Lemli-Opitz syndrome. Am. J. Med. Genet. 1994; 50:364-367. [PubMed: 8209917]

48. Batta AK, Tint GS, Salen G, Shefer S, Irons M, Elias ER. Identification of 7-dehydrocholesterol and related sterols in patients with Smith-Lemli-Opitz syndrome. Am. J. Med. Genet. 1994; 50:334.

49. Honda A, Salen G, Shefer S, Batta AK, Honda M, Xu G, Tint GS, Matsuzaki Y, Shoda J, Tanaka N. Bile acid synthesis in the Smith-Lemli-Opitz syndrome: effects of dehydrocholesterols on cholesterol 7alpha-hydroxylase and 27-hydroxylase activities in rat liver. J. Lipid Res. 1999; 40:1520-1528. [PubMed: 10428990]

50. Charman CR, Ryan A, Tyrrell RM, Pearse AD, Arlett CF, Kurwa HA, Shortland G, Anstey A. Photosensitivity associated with the Smith-Lemli-Opitz syndrome. Br. J. Dermatol. 1998; 138:885-888. [PubMed: 9666840]

51. Valencia A, Rajadurai A, Carle AB, Kochevar IE. 7-Dehydrocholesterol enhances ultraviolet Ainduced oxidative stress in keratinocytes: roles of NADPH oxidase, mitochondria, and lipid rafts. Free Radic. Biol. Med. 2006; 41:1704-1718. [PubMed: 17145559]

52. Vaughan DK, Peachey NS, Richards MJ, Buchan B, Fliesler SJ. Light-induced exacerbation of retinal degeneration in a rat model of Smith-Lemli-Opitz syndrome. Exp. Eye Res. 2006; 82:496504. [PubMed: 16360150]

53. Wassif CA, Yu J, Cui J, Porter FD, Javitt NB. 27-Hydroxylation of 7- and 8-dehydrocholesterol in Smith-Lemli-Opitz syndrome: a novel metabolic pathway. Steroids. 2003; 68:497-502. [PubMed: 12906934]

54. Bjorkhem I, Starck L, Andersson U, Lutjohann D, von BS, Pikuleva I, Babiker A, Diczfalusy U. Oxysterols in the circulation of patients with the Smith-Lemli-Opitz syndrome: abnormal levels of 24S- and 27-hydroxycholesterol. J. Lipid Res. 2001; 42:366-371. [PubMed: 11254748] 
55. Rossi M, Federico G, Corso G, Parenti G, Battagliese A, Frascogna AR, Della CR, Dello RA, Strisciuglio P, Saggese G, et al. Vitamin D status in patients affected by Smith-Lemli-Opitz syndrome. J. Inherit. Metab Dis. 2005; 28:69-80. [PubMed: 15702407]

56. Zimmerman PA, Hercules DM, Naylor EW. Direct analysis of filter paper blood specimens for identification of Smith-Lemli-Opitz syndrome using time-of-flight secondary ion mass spectrometry. Am. J. Med. Genet. 1997; 68:300-304.

57. Griffiths WJ, Wang Y, Karu K, Samuel E, McDonnell S, Hornshaw M, Shackleton C. Potential of sterol analysis by liquid chromatography-tandem mass spectrometry for the prenatal diagnosis of Smith-Lemli-Opitz syndrome. Clin. Chem. 2008; 54:1317-1324. [PubMed: 18556335]

58. Honda A, Yamashita K, Miyazaki H, Shirai M, Ikegami T, Xu G, Numazawa M, Hara T, Matsuzaki Y. Highly sensitive analysis of sterol profiles in human serum by LC-ESI-MS/MS. J. Lipid Res. 2008; 49:2063-2073. [PubMed: 18503032]

59. Johnson DW, ten Brink HJ, Jakobs C. A rapid screening procedure for cholesterol and dehydrocholesterol by electrospray ionization tandem mass spectrometry. J. Lipid Res. 2001; 42:1699-1705. [PubMed: 11590227]

60. Paglia G, D'Apolito O, Gelzo M, Dello RA, Corso G. Direct analysis of sterols from dried plasma/ blood spots by an atmospheric pressure thermal desorption chemical ionization mass spectrometry (APTDCI-MS) method for a rapid screening of Smith-Lemli-Opitz syndrome. Analyst. 2010; 135:789-796. [PubMed: 20349543]

61. Nwokoro NA, Mulvihill JJ. Cholesterol and bile acid replacement therapy in children and adults with Smith-Lemli-Opitz (SLO/RSH) syndrome. Am. J. Med. Genet. 1997; 68:315-321. [PubMed: 9024566]

62. Tierney E, Nwokoro NA, Kelley RI. Behavioral phenotype of RSH/Smith-Lemli-Opitz syndrome. Ment. Retard. Dev. Disabil. Res. Rev. 2000; 6:131-134. [PubMed: 10899806]

63. Mueller C, Patel S, Irons M, Antshel K, Salen G, Tint GS, Bay C. Normal cognition and behavior in a Smith-Lemli-Opitz syndrome patient who presented with Hirschsprung disease. Am. J. Med. Genet. A. 2003; 123A:100-106. [PubMed: 14556255]

64. Tierney E, Nwokoro NA, Porter FD, Freund LS, Ghuman JK, Kelley RI. Behavior phenotype in the RSH/Smith-Lemli-Opitz syndrome. Am. J. Med. Genet. 2001; 98:191-200. [PubMed: 11223857]

65. Bukelis I, Porter FD, Zimmerman AW, Tierney E. Smith-Lemli-Opitz syndrome and autism spectrum disorder. Am. J. Psychiatry. 2007; 164:1655-1661. [PubMed: 17974928]

66. Sikora DM, Pettit-Kekel K, Penfield J, Merkens LS, Steiner RD. The near universal presence of autism spectrum disorders in children with Smith-Lemli-Opitz syndrome. Am. J. Med. Genet. A. 2006; 140:1511-1518. [PubMed: 16761297]

67. Tierney E, Bukelis I, Thompson RE, Ahmed K, Aneja A, Kratz L, Kelley RI. Abnormalities of cholesterol metabolism in autism spectrum disorders. Am. J. Med. Genet. B Neuropsychiatr. Genet. 2006; 141B:666-668. [PubMed: 16874769]

68. Arndt TL, Stodgell CJ, Rodier PM. The teratology of autism. Int. J. Dev. Neurosci. 2005; 23:189199. [PubMed: 15749245]

69. Johnson CP, Myers SM. Identification and evaluation of children with autism spectrum disorders. Pediatrics. 2007; 120:1183-1215. [PubMed: 17967920]

70. Bolanos JP, Medina JM, Williamson DH. Inhibition of sterol but not fatty acid synthesis by valproate in developing rat brain in vivo. Biochem. J. 1990; 272:251-253. [PubMed: 2264830]

71. Linck LM, Lin DS, Flavell D, Connor WE, Steiner RD. Cholesterol supplementation with egg yolk increases plasma cholesterol and decreases plasma 7-dehydrocholesterol in Smith-Lemli-Opitz syndrome. Am. J. Med. Genet. 2000; 93:360-365. [PubMed: 10951458]

72. Elias ER, Irons MB, Hurley AD, Tint GS, Salen G. Clinical effects of cholesterol supplementation in six patients with the Smith-Lemli-Opitz syndrome (SLOS). Am. J. Med. Genet. 1997; 68:305310. [PubMed: 9024564]

73. Martin A, Koenig K, Scahill L, Tierney E, Porter FD, Nwokoro NA. Smith-Lemli-Opitz syndrome. J. Am. Acad. Child Adolesc. Psychiatry. 2001; 40:506-507. [PubMed: 11349693] 
74. Sikora DM, Ruggiero M, Petit-Kekel K, Merkens LS, Connor WE, Steiner RD. Cholesterol supplementation does not improve developmental progress in Smith-Lemli-Opitz syndrome. J. Pediatr. 2004; 144:783-791. [PubMed: 15192627]

75. Tierney E, Conley SK, Goodwin H, Porter FD. Analysis of short-term behavioral effects of dietary cholesterol supplementation in Smith-Lemli-Opitz syndrome. Am. J. Med. Genet. A. 2010; 152A: 91-95. [PubMed: 20014133]

76. Azurdia RM, Anstey AV, Rhodes LE. Cholesterol supplementation objectively reduces photosensitivity in the Smith-Lemli-Opitz syndrome. Br. J. Dermatol. 2001; 144:143-145. [PubMed: 11167696]

77. Starck L, Lovgren-Sandblom A, Bjorkhem I. Cholesterol treatment forever? The first Scandinavian trial of cholesterol supplementation in the cholesterol-synthesis defect Smith-Lemli-Opitz syndrome. J. Intern. Med. 2002; 252:314-321. [PubMed: 12366604]

78. Jira PE, Wevers RA, De JJ, Rubio-Gozalbo E, Janssen-Zijlstra FS, van Heyst AF, Sengers RC, Smeitink JA. Simvastatin. A new therapeutic approach for Smith-Lemli-Opitz syndrome. J. Lipid Res. 2000; 41:1339-1346. [PubMed: 10946022]

79. Starck L, Lovgren-Sandblom A, Bjorkhem I. Simvastatin treatment in the SLO syndrome: a safe approach? Am. J. Med. Genet. 2002; 113:183-189. [PubMed: 12407710]

80. Haas D, Garbade SF, Vohwinkel C, Muschol N, Trefz FK, Penzien JM, Zschocke J, Hoffmann GF, Burgard P. Effects of cholesterol and simvastatin treatment in patients with Smith-Lemli-Opitz syndrome (SLOS). J. Inherit. Metab Dis. 2007; 30:375-387. [PubMed: 17497248]

81. Saheki A, Terasaki T, Tamai I, Tsuji A. In vivo and in vitro blood-brain barrier transport of 3hydroxy-3-methylglutaryl coenzyme A (HMG-CoA) reductase inhibitors. Pharm Res. 1994; 11(2): 305-311. [PubMed: 8165193]

82. Chan YM, Merkens LS, Connor WE, Roullet JB, Penfield JA, Jordan JM, Steiner RD, Jones PJ. Effects of dietary cholesterol and simvastatin on cholesterol synthesis in Smith-Lemli-Opitz syndrome. Pediatr. Res. 2009; 65:681-685. [PubMed: 19430384]

83. Wassif CA, Krakowiak PA, Wright BS, Gewandter JS, Sterner AL, Javitt N, Yergey AL, Porter FD. Residual cholesterol synthesis and simvastatin induction of cholesterol synthesis in SmithLemli-Opitz syndrome fibroblasts. Mol. Genet. Metab. 2005; 85:96-107. [PubMed: 15896653]

84. Vega GL, Weiner MF, Lipton AM, Von Bergmann K, Lutjohann D, Moore C, Svetlik D. Reduction in levels of 24S-hydroxycholesterol by statin treatment in patients with Alzheimer disease. Arch Neurol. 2003; 60(4):510-505. [PubMed: 12707064]

85. Matabosch X, Ying L, Serra M, Wassif CA, Porter FD, Shackleton C, Watson G. Increasing cholesterol synthesis in 7-dehydrosterol reductase (DHCR7) deficient mouse models through gene transfer. J. Steroid Biochem. Mol. Biol. 2010; 122:303-309. [PubMed: 20800683]

86. Lindegaard ML, Wassif CA, Vaisman B, Amar M, Wasmuth EV, Shamburek R, Nielsen LB, Remaley AT, Porter FD. Characterization of placental cholesterol transport: ABCA1 is a potential target for in utero therapy of Smith-Lemli-Opitz syndrome. Hum. Mol. Genet. 2008; 17:38063813. [PubMed: 18775956]

87. Irons MB, Nores J, Stewart TL, Craigo SD, Bianchi DW, D'Alton ME, Tint GS, Salen G, Bradley LA. Antenatal therapy of Smith-Lemli-Opitz syndrome. Fetal Diagn. Ther. 1999; 14:133-137. [PubMed: 10364662]

88. Correa-Cerro LS, Wassif CA, Waye JS, Krakowiak PA, Cozma D, Dobson NR, Levin SW, Anadiotis G, Steiner RD, Krajewska-Walasek M, et al. DHCR7 nonsense mutations and characterisation of mRNA nonsense mediated decay in Smith-Lemli-Opitz syndrome. J. Med. Genet. 2005; 42:350-357. [PubMed: 15805162]

89. Kim JH, Lee JN, Paik YK. Cholesterol biosynthesis from lanosterol. A concerted role for Sp1 and NF-Y-binding sites for sterol-mediated regulation of rat 7-dehydrocholesterol reductase gene expression. J. Biol. Chem. 2001; 276:18153-18160. [PubMed: 11279217]

90. Lee JN, Bae SH, Paik YK. Structure and alternative splicing of the rat 7-dehydrocholesterol reductase gene Biochim. Biophys Acta. 2002; 1576:148-156.

91. Nishino H, Ishibash T. Evidence for requirement of NADPH-cytochome P450 oxidaoreductase in the microsomal NADPH-sterol $\Delta 7$-reductase system. Archives Biochem Biophys. 2000; 374:293298. 
92. Bae SH, Lee JN, Fitzky BU, Seong J, Paik YK. Cholesterol biosynthesis from lanosterol. Molecular cloning, tissue distribution, expression, chromosomal localization, and regulation of rat 7-dehydrocholesterol reductase, a Smith-Lemli-Opitz syndrome-related protein. J. Biol. Chem. 1999; 274:14624-14631. [PubMed: 10329655]

93. Honda M, Tint GS, Honda A, Nguyen LB, Chen TS, Shefer S. 7-Dehydrocholesterol downregulates cholesterol biosynthesis in cultured Smith-Lemli-Opitz syndrome skin fibroblasts. J. Lipid Res. 1998; 39:647-657. [PubMed: 9548596]

94. Waterham HR, Wanders RJ. Biochemical and genetic aspects of 7-dehydrocholesterol reductase and Smith-Lemli-Opitz syndrome. Biochim. Biophys. Acta. 2000; 1529:340-356. [PubMed: 11111101]

95. Honda A, Tint GS, Salen G, Batta AK, Chen TS, Shefer S. Defective conversion of 7dehydrocholesterol to cholesterol in cultured skin fibroblasts from Smith-Lemli-Opitz syndrome homozygotes. J. Lipid Res. 1995; 36:1595-1601. [PubMed: 7595082]

96. Ginat S, Battaile KP, Battaile BC, Maslen C, Gibson KM, Steiner RD. Lowered DHCR7 activity measured by ergosterol conversion in multiple cell types in Smith-Lemli-Opitz syndrome. Mol. Genet. Metab. 2004; 83:175-183. [PubMed: 15464432]

97. Witsch-Baumgartner M, Gruber M, Kraft HG, Rossi M, Clayton P, Giros M, Haas D, Kelley RI, Krajewska-Walasek M, Utermann G. Maternal apo E genotype is a modifier of the Smith-LemliOpitz syndrome. J. Med. Genet. 2004; 41:577-584. [PubMed: 15286151]

98. Jenkins KT, Merkens LS, Tubb MR, Myatt L, Davidson WS, Steiner RD, Woollett LA. Enhanced placental cholesterol efflux by fetal HDL in Smith-Lemli-Opitz syndrome. Mol. Genet. Metab. 2008; 94:240-247. [PubMed: 18346920]

99. Jira PE, Wanders RJ, Smeitink JA, De JJ, Wevers RA, Oostheim W, Tuerlings JH, Hennekam RC, Sengers RC, Waterham HR. Novel mutations in the 7-dehydrocholesterol reductase gene of 13 patients with Smith--Lemli--Opitz syndrome. Ann. Hum. Genet. 2001; 65:229-236. [PubMed: 11427181]

100. Battaile KP, Battaile BC, Merkens LS, Maslen CL, Steiner RD. Carrier frequency of the common mutation IVS8-1G>C in DHCR7 and estimate of the expected incidence of Smith-Lemli-Opitz syndrome. Mol. Genet. Metab. 2001; 72:67-71. [PubMed: 11161831]

101. Nowaczyk MJ, Zeesman S, Waye JS, Douketis JD. Incidence of Smith-Lemli-Opitz syndrome in Canada: results of three-year population surveillance. J. Pediatr. 2004; 145:530-535. [PubMed: 15480380]

102. Waye JS, Nakamura LM, Eng B, Hunnisett L, Chitayat D, Costa T, Nowaczyk MJ. Smith-LemliOpitz syndrome: carrier frequency and spectrum of DHCR7 mutations in Canada. J. Med. Genet. 2002; 39:E31. [PubMed: 12070263]

103. Witsch-Baumgartner M, Fitzky BU, Ogorelkova M, Kraft HG, Moebius FF, Glossmann H, Seedorf U, Gillessen-Kaesbach G, Hoffmann GF, Clayton P, et al. Mutational spectrum in the Delta7-sterol reductase gene and genotype-phenotype correlation in 84 patients with SmithLemli-Opitz syndrome. Am. J. Hum. Genet. 2000; 66:402-412. [PubMed: 10677299]

104. Ciara E, Nowaczyk MJ, Witsch-Baumgartner M, Malunowicz E, Popowska E, Jezela-Stanek A, Piotrowicz M, Waye JS, Utermann G, Krajewska-Walasek M. DHCR7 mutations and genotypephenotype correlation in 37 Polish patients with Smith-Lemli-Opitz syndrome. Clin. Genet. 2004; 66:517-524. [PubMed: 15521979]

105. Goluszko P, Nowicki B. Membrane cholesterol: a crucial molecule affecting interactions of microbial pathogens with mammalian cells. Infection \& Immunity. 2005; 73(12):7791-7796. [PubMed: 16299268]

106. Langius FA, Waterham HR, Romeijn GJ, Oostheim W, de Barse MM, Dorland L, Duran M, Beemer FA, Wanders RJ, Poll-The BT. Identification of three patients with a very mild form of Smith-Lemli-Opitz syndrome. Am. J. Med. Genet. A. 2003; 122A:24-29. [PubMed: 12949967]

107. Waye JS, Eng B, Nowaczyk MJ. Prenatal diagnosis of Smith-Lemli-Opitz syndrome (SLOS) by DHCR7 mutation analysis. Prenat. Diagn. 2007; 27:638-640. [PubMed: 17441222]

108. Jandacek RJ, Heubi JE, Tso P. A novel, noninvasive method for the measurement of intestinal fat absorption. Gastroenterology. 2004; 127(1):139-144. [PubMed: 15236180] 
109. Liss J, Lukaszuk K, Bruszczynska A, Szczerkowska Z, Rebala K. Pregnancy and life after preimplantation genetic diagnosis of Smith-Lemli-Opitz syndrome. Fertil. Steril. 2008; 90:20112016. [PubMed: 18442819]

110. Roux C, Horvath C, Dupuis R. Teratogenic action and embryo lethality of AY9944R Prevention by a hypercholesterolemia provoking diet. Teratology. 1979; 19:35-38. [PubMed: 88081]

111. Roux C, Dupuis R, Horvath C, Talbot JN. Teratogenic effect of an inhibitor of cholesterol synthesis (AY 9944) in rats: correlation with maternal cholesterolemia. J.Nutr. 1980; 110:2310 2312. [PubMed: 6159463]

112. Barbu V, Roux C, Lambert D, Dupuis R, Gardette J, Maziere JC, Maziere C, Elefant E, Polonovski J. Cholesterol prevents the teratogenic action of AY 9944: importance of the timing of cholesterol supplementation to rats. J.Nutr. 1988; 118:774-779. [PubMed: 2453625]

113. Wolf C, Chevy F, Pham J, Kolf-Clauw M, Citadelle D, Mulliez N, Roux C. Changes in serum sterols of rats treated with 7-dehydrocholesterol-delta 7-reductase inhibitors: comparison to levels in humans with Smith-Lemli-Opitz syndrome. J. Lipid Res. 1996; 37:1325-1333. [PubMed: 8808767]

114. Gaoua W, Chevy F, Roux C, Wolf C. Oxidized derivatives of 7-dehydrocholesterol induce growth retardation in cultured rat embryos: a model for antenatal growth retardation in the SmithLemli-Opitz syndrome. J. Lipid Res. 1999; 40:456-463. [PubMed: 10064734]

115. Chevy F, Illien F, Wolf C, Roux C. Limb malformations of rat fetuses exposed to a distal inhibitor of cholesterol biosynthesis. J Lipid Res. 2002; 43:1192-1200. [PubMed: 12177163]

116. Roux C, Wolf C, Mulliez N, Gaoua W, Cormier V, Chevy F, Citadelle D. Role of cholesterol in embryonic development. Am. J. Clin. Nutr. 2000; 71:1270S-1279S. [PubMed: 10799401]

117. Gaoua W, Wolf C, Chevy F, Ilien F, Roux C. Cholesterol deficit but not accumulation of aberrant sterols is the major cause of the teratogenic activity in the Smith-Lemli-Opitz syndrome animal model. J. Lipid Res. 2000; 41:637-646. [PubMed: 10744785]

118. Marcos J, Shackleton CH, Buddhikot MM, Porter FD, Watson GL. Cholesterol biosynthesis from birth to adulthood in a mouse model for 7-dehydrosterol reductase deficiency (Smith-LemliOpitz syndrome). Steroids. 2007; 72:802-808. [PubMed: 17714750]

119. Patti GJ, Shriver LP, Wassif CA, Woo HK, Uritboonthai W, Apon J, Manchester M, Porter FD, Siuzdak G. Nanostructure-initiator mass spectrometry (NIMS) imaging of brain cholesterol metabolites in Smith-Lemli-Opitz syndrome. Neuroscience. 2010; 170:858-864. [PubMed: 20670678]

120. Yu H, Li M, Tint GS, Chen J, Xu G, Patel SB. Selective reconstitution of liver cholesterol biosynthesis promotes lung maturation but does not prevent neonatal lethality in Dhcr7 null mice. BMC. Dev. Biol. 2007; 7:27. [PubMed: 17408495]

121. Yu H, Wessels A, Tint GS, Patel SB. Partial rescue of neonatal lethality of Dhcr7 null mice by a nestin promoter-driven DHCR7 transgene expression. Brain Res. Dev. Brain Res. 2005; 156:4660.

122. Jiang XS, Backlund PS, Wassif CA, Yergey AL, Porter FD. Quantitative proteomics analysis of inborn errors of cholesterol synthesis: identification of altered metabolic pathways in DHCR7 and SC5D deficiency. Mol. Cell Proteomics. 2010; 9:1461-1475. [PubMed: 20305089]

123. Ford DA, Monda JK, Brush RS, Anderson RE, Richards MJ, Fliesler SJ. Lipidomic analysis of the retina in a rat model of Smith-Lemli-Opitz syndrome: alterations in docosahexaenoic acid content of phospholipid molecular species. J. Neurochem. 2008; 105:1032-1047. [PubMed: 18182048]

124. Boesze-Battaglia K, mek-Poprawa M, Mitchell DC, Greeley L, Brush RS, Anderson RE, Richards MJ, Fliesler SJ. Alteration of retinal rod outer segment membrane fluidity in a rat model of Smith-Lemli-Opitz syndrome. J. Lipid Res. 2008; 49:1488-1499. [PubMed: 18344409]

125. Caruso PA, Poussaint TY, Tzika AA, Zurakowski D, Astrakas LG, Elias ER, Bay C, Irons MB. MRI and 1H MRS findings in Smith-Lemli-Opitz syndrome. Neuroradiology. 2004; 46:3-14. [PubMed: 14605787]

126. Kroll RA, Neuwelt EA. Outwitting the blood-brain barrier for therapeutic purposes: osmotic opening and other means. Neurosurgery. 1998; 42:1083-1099. [PubMed: 9588554] 
127. Cartier N, Hacein-Bey-Abina S, Bartholomae CC, Veres G, Schmidt M, Kutschera I, Vidaud M, Abel U, Dal-Cortivo L, Caccavelli L, et al. Hematopoietic stem cell gene therapy with a lentiviral vector in X-linked adrenoleukodystrophy. Science. 2009; 326:818-823. [PubMed: 19892975]

128. Woollett LA. Where does fetal and embryonic cholesterol originate and what does it do? Annu. Rev. Nutr. 2008; 28:97-114. [PubMed: 18662139]

129. Ullrich K, Koch HG, Meschede D, Flotmann U, Seedorf U. Smith-Lemli-Opitz syndrome: treatment with cholesterol and bile acids. Neuropediatrics. 1996; 27:111-112. [PubMed: 8737829]

130. Rodrigues CM, Spellman SR, Solá S, Grande AW, Linehan-Stieers C, Low WC, Steer CJ. Neuroprotection by a bile acid in an acute stroke model in the rat. J Cereb Blood Flow Metab. 2002; 22:463-471. [PubMed: 11919517] 


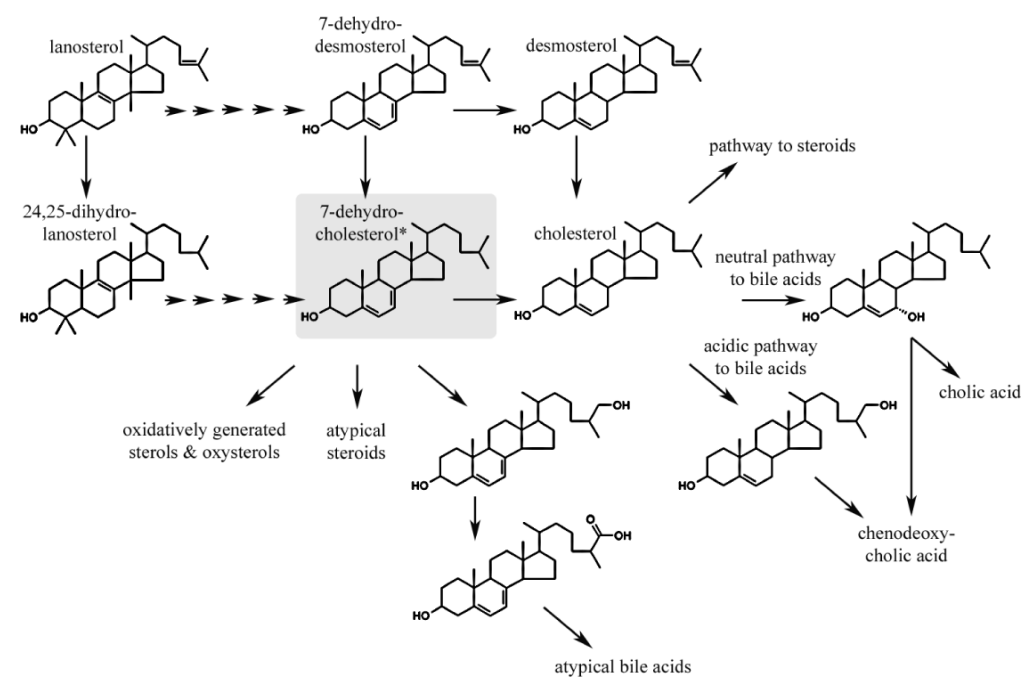

Figure 1. Biochemical Pathways in SLOS

SLOS patients experience a broad range of biochemical consequences stemming from elevated 7-DHC and deficiency in cholesterol. As cholesterol is a precursor in the synthesis of steroid hormones, bile acids and oxysterols, these compounds may be deficient in SLOS patients. Conversely atypical sterols, oxysterols, steroid hormones and bile acids are formed from 7- and 8-DHC. Atypical bile acids appear to be formed in "acidic pathway" via 27hydroxylation; formation of 27-hydroxylated 7- and 8-DHC (53) and conversion to $3 \beta$ hydroxycholestandienoic acids (49) has been demonstrated.

*Can isomerize to form 8-DHC. 



Figure 2.

Part A: Typical facial features of Smith-Lemli-Opitz syndrome: microcephaly, bitemporal narrowing, ptosis, short nasal root, anteverted nares and micrognathia. Part B: Toe syndactyly in Smith-Lemli-Opitz syndrome. Part C: Smith-Lemli-Opitz syndrome with mild phenotype. These pictures were obtained and are reproduced with informed consent. 


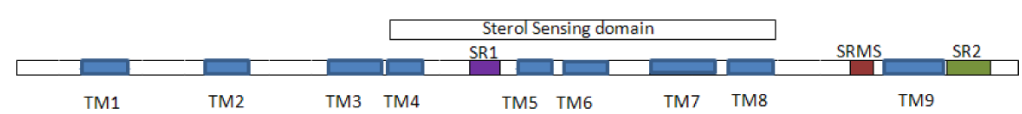

Figure 3.

Diagram of the DHCR7 protein identifying the putative locations of the 9 transmembrane regions: TM1-9 (blue), the 3 Sterol Reductase motifs: SR1 (purple), SR2 (green) SRMS (red) and the Sterol Sensing domain 


\section{Table 1}

Clinical features of SLOS.

\begin{tabular}{ll}
\hline General: & Failure to thrive, developmental delay, mental retardation, hypotonia, Insomnia, self-injurious/aggressive behaviors, autism \\
Skin: & Photosensitivity, eczema \\
Head: & $\begin{array}{l}\text { Microcephaly, bitemporal narrowing, broad nose with anteverted nares, micrognathia, arched palate, cleft palate/uvula, } \\
\text { holoprosencephaly, }\end{array}$ \\
Eyes: & Ptosis, epicanthal folds, strabismus, cataracts, optic nerve hypoplasia/atrophy \\
Cardiac: & Atrial septal defect, ventricular septal defect, patent ductus arteriosus, atrioventricular canal, hypertension \\
Gastrointestinal: & Pyloric stenosis, Hirschprung's disease, malrotation, constipation, reflux, feeding problems, cholestatic liver disease \\
Urogenital: & sexual ambiguity, hypospadias, cryptorchidism, renal malformations \\
Limbs: & rhizomelia, 2-3 toe syndactyly, polydactily, short thumbs References (19,24). \\
\hline
\end{tabular}

